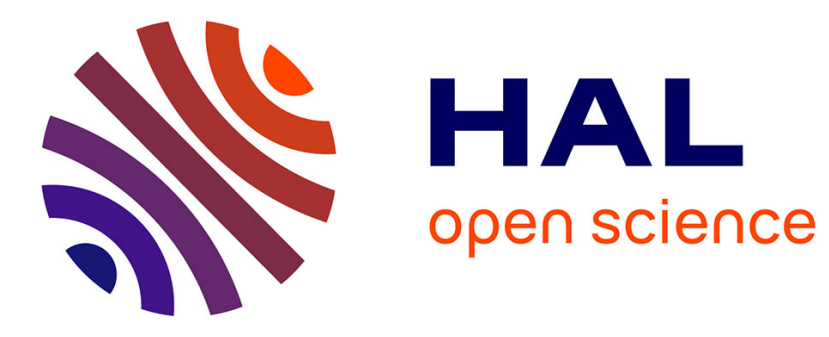

\title{
Permanent tremor reduction during thalamic stimulation in Multiple Sclerosis
}

Wesley Thevathasan, Patrick Schweder, Carole Joint, Nicola Ray, Pieter Pretorius, Ralph Gregory, Tipu Aziz

\section{- To cite this version:}

Wesley Thevathasan, Patrick Schweder, Carole Joint, Nicola Ray, Pieter Pretorius, et al.. Permanent tremor reduction during thalamic stimulation in Multiple Sclerosis. Journal of Neurology, Neurosurgery and Psychiatry, 2010, 82 (4), pp.419. 10.1136/jnnp.2010.213900 . hal-00581009

\section{HAL Id: hal-00581009 \\ https://hal.science/hal-00581009}

Submitted on 30 Mar 2011

HAL is a multi-disciplinary open access archive for the deposit and dissemination of scientific research documents, whether they are published or not. The documents may come from teaching and research institutions in France or abroad, or from public or private research centers.
L'archive ouverte pluridisciplinaire HAL, est destinée au dépôt et à la diffusion de documents scientifiques de niveau recherche, publiés ou non, émanant des établissements d'enseignement et de recherche français ou étrangers, des laboratoires publics ou privés. 


\section{Permanent tremor reduction during thalamic stimulation in Multiple Sclerosis}

Wesley Thevathasan FRACP, ${ }^{1,2,3,{ }^{*}}$ Patrick Schweder MBChB,${ }^{1,4}$ Carole Joint PhD, ${ }^{4}$ Nicola Ray DPhil, ${ }^{1}$ Pieter Pretorius FRCR, ${ }^{5}$ Ralph Gregory, FRCP, ${ }^{3}$ Tipu Aziz FRCS ${ }^{1,4}$

${ }^{1}$ Nuffield Department of Surgery, University of Oxford, UK

${ }^{2}$ Sobell Department of Motor Neuroscience and Movement Disorders, Institute of Neurology, Queen Square, London, UK

${ }^{3}$ Department of Neurology, John Radcliffe Hospital, Oxford, UK

${ }^{4}$ Department of Neurosurgery, John Radcliffe Hospital, Oxford, UK

${ }^{5}$ Department of Neuroradiology, John Radcliffe Hospital, Oxford, UK

*Correspondence to:

Dr Wesley Thevathasan

Department of Neurology, John Radcliffe Hospital, Oxford, OX3 9DU

Email: wesley.thevathasan@nds.ox.ac.uk

Tel +44 (0) 1865 741166; Fax +44 (0) 1865231870

Key words: Multiple sclerosis; Demyelination; Tremor; Thalamic; Stimulation Statistical analysis was performed by the first (corresponding) author (WT)

Counts:

Title character count $=76 ;$ Abstract $=252 ;$ Main text word count $=2036 ;$ References $=12$ Tables $=2$; Figures $=2$; Supplementary material $=1$ 


\begin{abstract}
Background: Unlike thalamic lesioning, thalamic stimulation is considered a reversible treatment for tremor. However, tremor in Multiple Sclerosis (MS) can sometimes permanently improve during thalamic stimulation. Such 'permanent tremor reduction' (PTR) has been attributed to limb weakness preventing tremor expression.
\end{abstract}

In this study, eleven consecutive patients with MS tremor treated with thalamic stimulation were assessed for PTR. Eighteen upper limbs had tremor, of which sixteen received contralateral stimulation.

Methods: Tremor severity and limb strength were assessed preoperatively, early postoperatively (within one year) and late postoperatively (after three years). Tremor severity was rated using validated clinical scales both on and off stimulation. Following explantation, the parenchyma surrounding three electrode tracts was examined with MRI.

Results: At final review (mean 5.2 years) PTR was evident in eleven of the eighteen upper limbs with tremor. PTR often rendered stimulation redundant. PTR could occur when limb strength was conserved and could arise remotely from the initial surgery. PTR was significant (and universal) in limbs that received long term ( $>2$ years), effective (tremor suppressing) stimulation. PTR was not a significant finding in limbs that had not received long term, effective stimulation. Contralateral to a limb with PTR, MRI revealed a thalamic lesion adjacent to the electrode tract. Thalamic lesions were not identified contralateral to two limbs without PTR.

Conclusions: MS tremor often permanently improves during thalamic stimulation, even when limb strength is conserved. PTR may simply reflect natural history. Alternatively, our 
findings appear consistent with the recent proposal that thalamic stimulation in MS might promote local "demyelinative lesioning".

\section{Introduction}

Thalamic lesioning and thalamic deep brain stimulation (DBS) are therapeutic options for severe, medication refractory tremor in multiple sclerosis (MS).[1, 2]

Whereas lesioning is permanent, stimulation is acutely reversible. For example, switching off thalamic stimulation should result in 'rebound' of tremor to pre-stimulation amplitudes.

However, it has been observed that tremor in MS can sometimes permanently reduce during the course of chronic thalamic stimulation. $[3,4]$ Hitherto, this permanent tremor reduction (PTR) has been attributed to limb weakness (occurring with MS disease progression) preventing the expression of tremor.[4]

In this study, we assessed a consecutive cohort of patients with MS tremor treated with long term thalamic stimulation. Tremor severity was rated both on and off stimulation over time. Tremor scores were correlated with limb strength and the duration and effectiveness of stimulation.

\section{Methods}

\section{$\underline{\text { Subjects }}$}

The study group comprised sixteen consecutive upper limbs with MS tremor treated with contralateral thalamic stimulation in eleven patients. Additionally there were two upper limbs 
with tremor that did not receive stimulation (two patients had bilateral tremor but received only unilateral stimulation). Surgery was performed by the same surgeon (TA) at least three years previously (1999-2006) at a single centre (Oxford).

All patients met diagnostic criteria for MS and had severe medication refractory tremor. Baseline clinical features were as follows (Mean \pm SD).; Age 38.7 \pm 11 years; 8 female, 3 male; MS duration 12.2 \pm 7.4 years; Extended Disability Status Score (EDSS) 7.2 \pm 1.1 . In all cases, tremor was predominant in the upper limbs and occurred with posture and action. No patient had rest tremor. Seven patients had bilateral tremor and four unilateral.

Under local anaesthesia, quadripolar electrodes (Model 3387, Medtronic) were inserted into the ventral oralis posterior (VOP) nucleus of the thalamus and zona incerta (ZI), as described previously.[5] Positioning was confirmed on postoperative CT fused with preoperative MRI. Stimulation parameters were as follows (Mean \pm SD); frequency $130 \mathrm{~Hz}$ or $180 \mathrm{~Hz}$, pulse width $216 \pm 99$ usec, voltage $3.8 \pm 1.2 \mathrm{v}$.

There were no acute infective or haemorrhagic complications. In one patient, the DBS system was removed due to persistent scalp erosion over the extension cables. One patient experienced self limited focal seizures in the immediate postoperative period without an identifiable structural lesion on imaging.

\section{$\underline{\text { Clinical assessments }}$}

Tremor severity was assessed preoperatively, early postoperatively (within twelve months) and late postoperatively (after at least 3 years).

Assessments were performed both on and off stimulation using clinical scoring methods specifically validated for MS tremor; the Clinical Rating Scale (CRS) and grading an 
Archimedes spiral drawing.[6] CRS was rated during posture (P-CRS, score/10) and movement (M-CRS, score/10) then summated to yield the total CRS score (T-CRS, score/20). Discriminating between action and intention components of movement related tremor is poorly reliable and was therefore not performed.[6] Archimedes spiral drawings (by the dominant hand, if stimulated) were graded (score/10), with higher scores indicating a worse spiral. Tremor was assessed unblinded from videotape recordings by a neurologist specialised in movement disorders (WT). Off stimulation assessments occurred at least 20 minutes after stopping stimulation, a period shown to be sufficient for $>90 \%$ of Parkinsonian tremor to return following cessation of stimulation.[7]

Upper limb strength was scored using the Medical Research Council (MRC) scale (score/5). The average of the MRC scores for shoulder abduction and finger extension was calculated for each upper limb. This method was used to capture weakness relevant to the expression of proximal and distal upper limb tremor, as utilised previously in the assessment of MS tremor during DBS.[4]

Local ethics committee approval was obtained and participants gave informed consent.

\section{$\underline{\text { Radiological assessments }}$}

MRI was performed to assess the parenchyma adjacent to electrode tracts. In subjects with DBS systems in situ, the artefact associated with the electrodes prevented useful assessment of the immediately surrounding parenchyma. We therefore limited MRI assessments to those where DBS systems had been explanted.

The imaging protocol included axial fluid attenuated inversion recovery (FLAIR) and T2weighted sequences acquired on a Philips Achieva ${ }^{\circledR}$ 1.5 Tesla Magnet (see supplementary 
material). Electrode tracts were identified in cross section on axial views and if required, longitudinally on coronal and sagittal reconstructions of the axial images.

The distal $12 \mathrm{~mm}$ of the Medtronic 3387 electrode contains the $1.5 \mathrm{~mm}$ inactive tip and four $1.5 \mathrm{~mm}$ contacts (spaced $1.5 \mathrm{~mm}$ apart) through which stimulation can be delivered. However, termination of the tract signal on MRI could not be assumed to reflect the position of the electrode tip during stimulation as electrode depth was often adjusted in theatre before securing the final position. We therefore conservatively estimated that stimulation could have been delivered up to $30 \mathrm{~mm}$ proximal to tract termination.

Lesion localisation was performed if appropriate using stereotactic planning software (Radionics, MS, USA) to calculate Cartesian coordinates relative to the Anterior Commissure-Posterior Commissure (AC-PC) plane and referencing to the histological Schaltenbrand-Wahren atlas.

\section{Results}

\section{$\underline{\text { Clinical assessments }}$}

Early (<1 year) postoperative outcomes

For the sixteen limbs that received contralateral stimulators, the mean T-CRS improved by $44 \%$ with stimulation (14.8 to 8.3, Wilcoxon $\mathrm{p}=0.002, \mathrm{z}=-3.063$ ) (table 2). However, the response to stimulation was variable and improvements in T-CRS ranged from $0-86 \%$. In four upper limbs (of two patients), T-CRS and spiral scores did not improve with stimulation, however stimulation was continued due to subjective benefits. Six patients regained the ability to drink from a cup or beaker from a tremulous limb. 
In the early postoperative period, tremor severity was also assessed in five upper limbs after switching stimulation off. In four of these, the T-CRS scores 'off stimulation' were identical to preoperative scores. In one limb, the off stimulation T-CRS score was lower than the preoperative score, but stimulation remained beneficial.

\section{Late (> 3 years) postoperative outcomes}

By final review (5.2 \pm 1.8 years), PTR had developed in ten of the sixteen upper limbs that received contralateral stimulation. In eight, T-CRS scores 'off stimulation' were even less than their previous 'on stimulation' scores (from the early postoperative period). PTR was often not recognised. In many cases, stimulation had become redundant and batteries had depleted without the patient noticing. In six limbs PTR was observed despite stimulation having ceased over a year previously (a finding inconsistent with PTR being simply due to delayed 'washout' of stimulation).

All ten upper limbs that developed PTR during DBS had received long term (>2 years) and effective (tremor score suppressing) stimulation. In two, it was possible that severe weakness $(\mathrm{MRC}=2)$ was preventing tremor expression. However, PTR remained a significant finding in the remaining eight limbs where limb strength had been conserved (MRC $\geq 4$ ), (mean T-CRS 13.6 Vs 5.2, Wilcoxon $\mathrm{p}=0.012, \mathrm{z}=-2.527)$ (table 2, figure 1a).

Six upper limbs that received contralateral stimulation did not develop PTR. However, none of these six limbs had received effective, long term stimulation. In four (two patients), stimulation had been ineffective (could not suppress tremor scores). Two upper limbs (one patient) had received effective stimulation but after a year the DBS system had to be removed (due to scalp erosion over the extension cables) and tremor rebounded to preoperative levels 
and persisted to final follow up (at 5 years). Additionally, there were two upper limbs with tremor that did not receive a contralateral stimulator (in patients with bilateral tremor but unilateral stimulators) - tremor reduced in one and worsened in the other. There were, therefore, a total of eight limbs with tremor that did not receive long term, effective stimulation (table 2, figure 1b). For this group, off stimulation T-CRS scores were not significantly different to preoperatively (mean 13.8 Vs 13.4 , Wilcoxon $\mathrm{p}=0.593, \mathrm{z}=-0.535$ ).

Of the five limbs that were assessed 'off stimulation' in the first postoperative year, PTR ultimately developed in three. In two, PTR had developed wholly after that first assessment. In one limb, PTR had progressed since the first assessment.

\section{$\underline{\text { Radiological assessments }}$}

DBS hardware was removed following thalamic stimulation in two patients (patients 3 and 6), permitting MRI assessment of three electrode tracts (figure 2). In both cases, MRI disclosed extensive (>30) white matter lesions with morphology, signal characteristics and distribution consistent with MS.

Patient 3 had left thalamic stimulation for unilateral right sided tremor. Monopolar stimulation was applied through the lowest contact at 130Hz/2.7Volts/90usec. After 3.8 years, PTR developed and stimulation became unnecessary. The DBS system was explanted on the patient's request. On MRI, the electrode tract could not be definitively identified along its course through white matter. However tract signal was identified in the thalamus as a discrete, sharply demarcated hyperintensity of approximately $1.5 \mathrm{~mm}$ diameter on $\mathrm{T} 2$ and FLAIR images. Cartesian coordinates for this location corresponded to the motor thalamus (at the junction of VIM and VOP) on the Schaltenbrand-Wahren atlas. Directly adjacent to, 
and partially surrounding the tract, a small area of slightly less markedly elevated signal was evident on both T2 and FLAIR images (fig $2 \mathrm{a}$ and $\mathrm{b}$ ). This lesion measured $5 \mathrm{~mm} \times \mathrm{mm} x$ $6 \mathrm{~mm}$ in XYZ planes. The lesion was not present on preoperative imaging.

Patient 6 had bilateral tremor successfully suppressed with bilateral DBS. Bipolar stimulation had been applied at 130Hz/330usec bilaterally, left 3.2volts and right 3.4volts. After 1 year the DBS system was removed due to hardware complications and tremor recurred. On T2 and FLAIR, electrode tracts appeared as well defined hypointense signal intensities passing from frontal gyral cortex through white matter and lateral thalami. Due to severe ventricular dilatation and substantial atrophy, atlas based localisation was not appropriate. Inspection of brain parenchyma surrounding the distal $30 \mathrm{~mm}$ of the tract (including the thalami) did not reveal any neighbouring focal white matter lesions (figure 2c). Elsewhere, both electrodes did traverse regions of widespread demyelination, however discrete focal demyelination adjacent to tract signal was not observed.

\section{Discussion}

In this study, we found that it is common for MS tremor to permanently improve during long term thalamic stimulation. Permanent tremor reduction occurred even when limb strength had been conserved. This suggests that tremor itself diminished rather than the expression of tremor being prevented by severe weakness, as had been suggested previously.[4]

Permanent reduction of MS tremor during DBS may simply reflect natural history. For example, we observed PTR in a limb that had not received any contralateral stimulation. However, spontaneous remission of MS tremor is not reported to be common. For example, in a study of 100 outpatients with MS, 31 had tremor and none reported tremor remission.[8] 
Another possibility is that DBS promotes PTR. For example, electrode implantation can cause a 'persistent microthalamotomy'. However, we observed PTR to begin or progress after the first postoperative assessment. This leaves open the possibility that chronic DBS elements may promote PTR, such as the presence of implanted electrodes or the electrical stimulation. Accordingly, PTR was found to be significant following long term, effective stimulation but not with short term or ineffective stimulation.

The first pathological study of a patient with MS tremor treated with thalamic stimulation has recently been reported.[9] In the thalamus on post mortem, focal demyelination was detected between the electrode cathode and anode, diminishing with distance from the centre of the electrical field. The authors postulated that electrical stimulation could have contributed to demyelination at that site, causing a thalamotomy. This lesioning hypothesis would be consistent with the time course of PTR that we observed. Additionally, it would explain why PTR occurred when stimulation had been effective (suppressed tremor), as tremor reduction from lesioning can be predicted by tremor suppression from stimulation.[10] In MS tremor, there is a variable contribution of ataxia to the overall tremor phenotype.[11, 12]Ataxic tremor responds poorly to both stimulation and lesioning - potentially explaining why MS tremor responds so variably to stimulation and why four limbs failed to achieve tremor suppression with DBS and subsequently failed to develop PTR.[11, 12]

In the absence of pathological findings from patients in this study, we assessed the parenchyma surrounding electrode tracts with MRI (in cases where DBS systems had been explanted). We caution that the MRI findings are not conclusive. However the findings do appear consistent with stimulation associated lesioning. Two limbs had not developed PTR and contralateral thalamic lesions were not seen. One limb had developed PTR and a lesion was evident in the contralateral motor thalamus, adjacent to the tract of the stimulating 
portion of the electrode. Thalamic demyelination is known to occur spontaneously in MS.[13] Whether such lesioning might be further promoted by DBS needs further research.

Clinically, the PTR phenomenon is important to recognise. We would recommend that the persistence of tremor 'off stimulation' should be determined, to avoid unnecessary replacement of batteries nearing depletion.

Ethical approval Ethical approval was obtained from the local ethics committee and patient consent was obtained.

Funding No external funding

Competing Interests: TA has received research funding and honoraria from Medtronic and St Jude's Medical.

\section{Licence for Publication:}

The Corresponding Author has the right to grant on behalf of all authors and does grant on behalf of all authors, an exclusive licence (or non exclusive for government employees) on a worldwide basis to the BMJ Publishing Group Ltd and its Licensees to permit this article (if accepted) to be published in the Journal of Neurology, Neurosurgery \& Psychiatry editions and any other BMJPGL products to exploit all subsidiary rights, as set out in our licence (http://jnnp .bmjjournals.com/ifora/licence.pdf).

Acknowledgements: This work was supported by: The Oxford Biomedical Research Centre, The Medical Research Council, UK, The Charles Wolfson Charitable Foundation and the Norman Collisson Foundation. 


\section{References:}

1 Brice J, McLellan L. Suppression of intention tremor by contingent deep-brain stimulation. Lancet 1980;1:1221-2.

2 Alusi SH, Aziz TZ, Glickman S, et al. Stereotactic lesional surgery for the treatment of tremor in multiple sclerosis: a prospective case-controlled study. Brain 2001;124:1576-89.

3 Moringlane JR, Spiegel J, Fuss G, et al. Improvement of upper limb ataxia and intention tremor allowing cessation of thalamic electrostimulation after four years. Mult Scler 2004;10:708-10.

4 Hyam JA, Aziz TZ, Bain PG. Post-deep brain stimulation--gradual non-stimulation dependent decrease in strength with attenuation of multiple sclerosis tremor. J Neurol 2007;254:854-60.

5 Nandi D, Aziz TZ. Deep brain stimulation in the management of neuropathic pain and multiple sclerosis tremor. J Clin Neurophysiol 2004;21:31-9.

6 Alusi SH, Worthington J, Glickman S, et al. Evaluation of three different ways of assessing tremor in multiple sclerosis. J Neurol Neurosurg Psychiatry 2000;68:756-60.

7 Temperli P, Ghika J, Villemure JG, et al. How do parkinsonian signs return after discontinuation of subthalamic DBS? Neurology 2003;60:78-81.

8 Alusi SH, Worthington J, Glickman S, et al. A study of tremor in multiple sclerosis. Brain 2001;124:720-30.

9 Moore GR, Vitali AM, Leung E, et al. Thalamic stimulation in multiple sclerosis: evidence for a 'demyelinative thalamotomy'. Mult Scler 2009;15:1311-21.

10 Hassler R. The influence of stimulations and coagulations in the human thalamus on the tremor at rest and its physiopathologic mechanism. Proceedings of the Second International Congress of Neuropathology 1955;2:637-42.

11 Liu X, Aziz TZ, Miall RC, et al. Frequency analysis of involuntary movements during wrist tracking: a way to identify ms patients with tremor who benefit from thalamotomy. Stereotact Funct Neurosurg 2000;74:53-62.

12 Liu X, Miall C, Aziz TZ, et al. Analysis of action tremor and impaired control of movement velocity in multiple sclerosis during visually guided wrist-tracking tasks. Mov Disord 1997;12:992-9.

13 Vercellino M, Plano F, Votta B, et al. Grey matter pathology in multiple sclerosis. $J$ Neuropathol Exp Neurol 2005;64:1101-7. 
Thevathasan 13

\begin{tabular}{|c|c|c|c|c|}
\hline & $\begin{array}{c}\text { T-CRS score } / 20 \\
\text { (stimulated limbs) } \\
\mathrm{N}=16\end{array}$ & $\begin{array}{c}\text { Spiral score } / 10 \\
\text { (dominant hand)** } \\
\mathrm{N}=11\end{array}$ & $\begin{array}{c}\text { Able to drink from a } \\
\text { beaker } \\
\text { (from limb receiving DBS) } \\
\mathrm{N} / 11\end{array}$ & EDSS /10 \\
\hline Preoperative & $14.8 \pm 2.5(9-18)$ & $8.6 \pm 2.1(5-10)$ & $0 / 11$ & $7.2 \pm 1.1(6-9)$ \\
\hline $\begin{array}{c}\text { Early Postoperative } \\
\text { (On Stim) }\end{array}$ & $8.3 \pm 4.9(2-17)^{+}$ & $6.4 \pm 2.5(4-10)^{*}$ & $6 / 11^{*}$ & $7.0 \pm 1.0(5.5-8.5)$ \\
\hline
\end{tabular}

Table 1: Early 'on stimulation' outcomes for the sixteen upper limbs of eleven patients that received contralateral DBS. Mean $\pm \mathrm{SD}($ range $) . * *$ Dominant hand unless only the non dominant hand received contralateral DBS. $* \mathrm{P}<0.05 ;{ }^{+} \mathrm{P}<0.01$ (Wilcoxon)

\begin{tabular}{|c|c|c|c|c|c|c|}
\hline & $\begin{array}{c}\text { Number } \\
(\mathrm{n} / 16)\end{array}$ & $\begin{array}{c}\text { Follow Up } \\
\text { (years postop) }\end{array}$ & $\begin{array}{c}\text { Initial } \\
\text { MRC score } \\
/ 5\end{array}$ & $\begin{array}{c}\text { Final } \\
\text { MRC score } \\
/ 5\end{array}$ & $\begin{array}{c}\text { Initial T-CRS } \\
\text { Score } \\
\text { (preop) } \\
/ 20\end{array}$ & $\begin{array}{c}\text { Final T-CRS score } \\
\text { (off stimulation) } \\
/ 20\end{array}$ \\
\hline $\begin{array}{c}\text { Tremor with } \\
\text { long term } \\
\text { effective DBS }\end{array}$ & 8 & $5.7 \pm 2.0(3.3-8.4)$ & $5 \pm 0$ & $4.6 \pm 0.5(4-5)$ & $13.6 \pm 2.4(9-16)$ & $5.2 \pm 3.3(1-10)^{*}$ \\
\hline $\begin{array}{c}\text { Tremor without } \\
\text { long term } \\
\text { effective DBS }\end{array}$ & 8 & $4.6 \pm 1.7(3.5-8.4)$ & $5 \pm 0$ & $4.8 \pm 0.5(4-5)$ & $13.8 \pm 3.7(6-18)$ & $13.4 \pm 4.0(5-18)$ \\
\hline
\end{tabular}

Table 2: Comparison of tremulous upper limbs with preserved strength that received long term effective stimulation and those that did not. Mean $\pm \mathrm{SD}$ (range). Differences between final and initial cores $* \mathrm{P}<0.05$ (Wilcoxon). There were no significant differences in mean follow up, initial or final MRC scores or initial T-CRS scores between the two groups (independent samples $t$ test). 
Figure 1: T-CRS scores of the 18 upper limbs with MS tremor (16 received contralateral stimulators and 2 did not). Timepoints are; preoperative baseline, one year postoperatively (on contralateral stimulation, if present) and long term follow up (off stimulation). 1a; Upper limbs with tremor that received effective, long term stimulation. 1b; Upper limbs with tremor that did not receive effective, long term stimulation.

Figure 2: Axial MRI images of patient 3 (2a and 2b) and patient 6 (2c) following removal of electrodes. 2a: FLAIR image demonstrating the hyperintense lesion in the motor thalamus (red arrow). 2b: Close up view of the left thalamus demonstrating the discrete hyperintense electrode tract (blue arrow) and the adjacent less clearly defined hyperintense lesion (yellow arrow). 2c: T2 image demonstrating the two electrode tracts visualised as discrete hypointensities (red arrows). 
Figure 1a

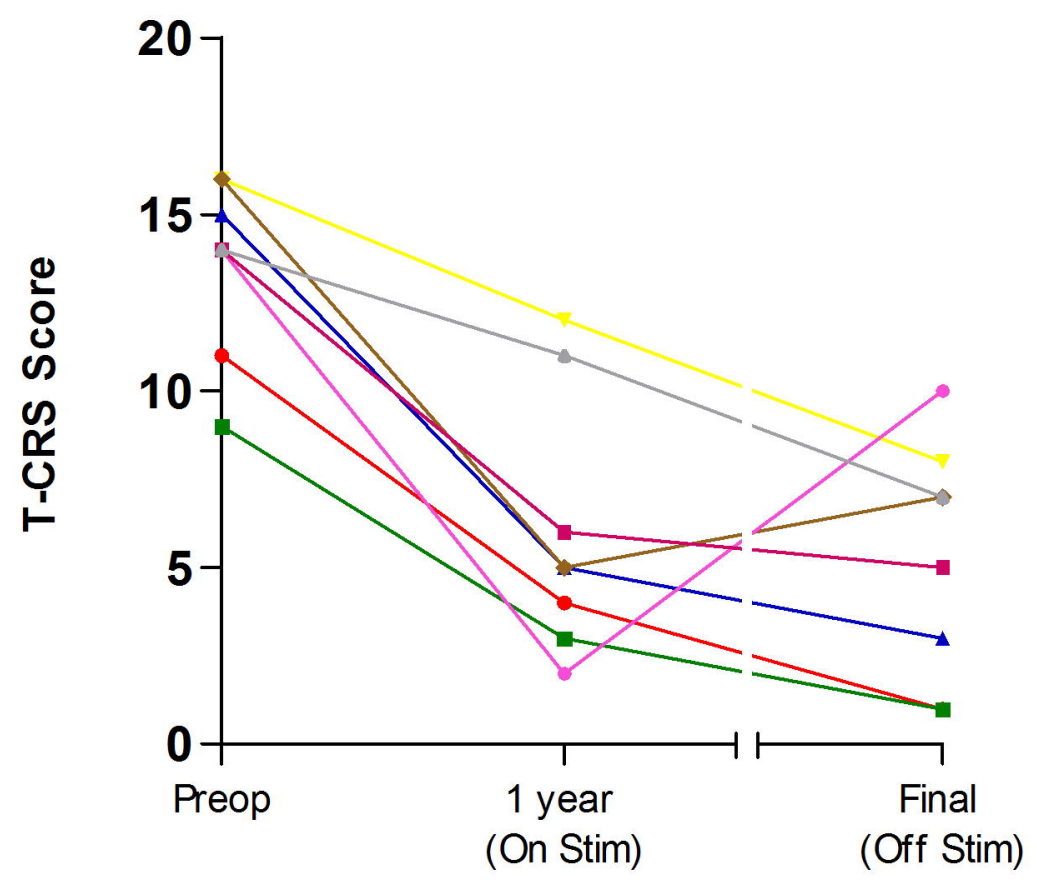

Figure 1b

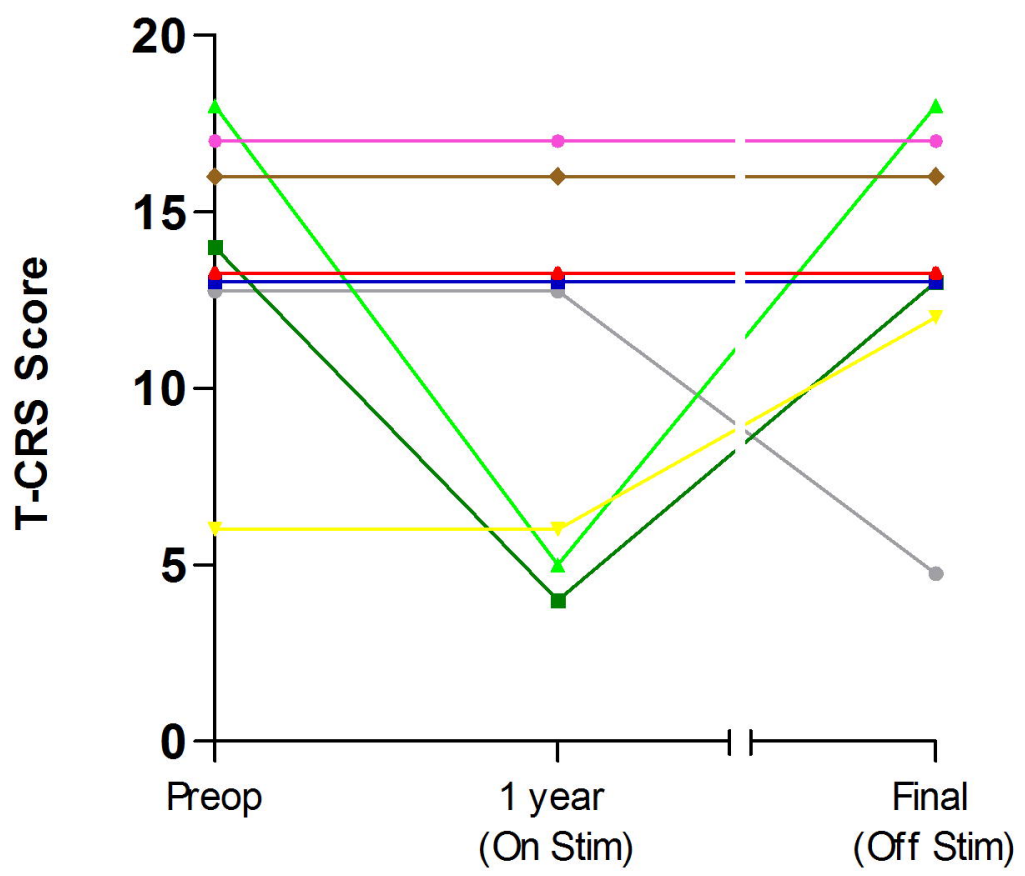

— Patient 1 Right arm

$\longrightarrow$ Patient 6 Right arm

$\longrightarrow \quad$ Patient 6 Left arm

Patient 7 Left arm

$\leadsto \quad$ Patient 10 Right arm

$\multimap \quad$ Patient 10 Left arm

$\longrightarrow$ Patient 11 Right arm

$\longrightarrow \quad$ Patient 11 Left arm 
Figure 2a

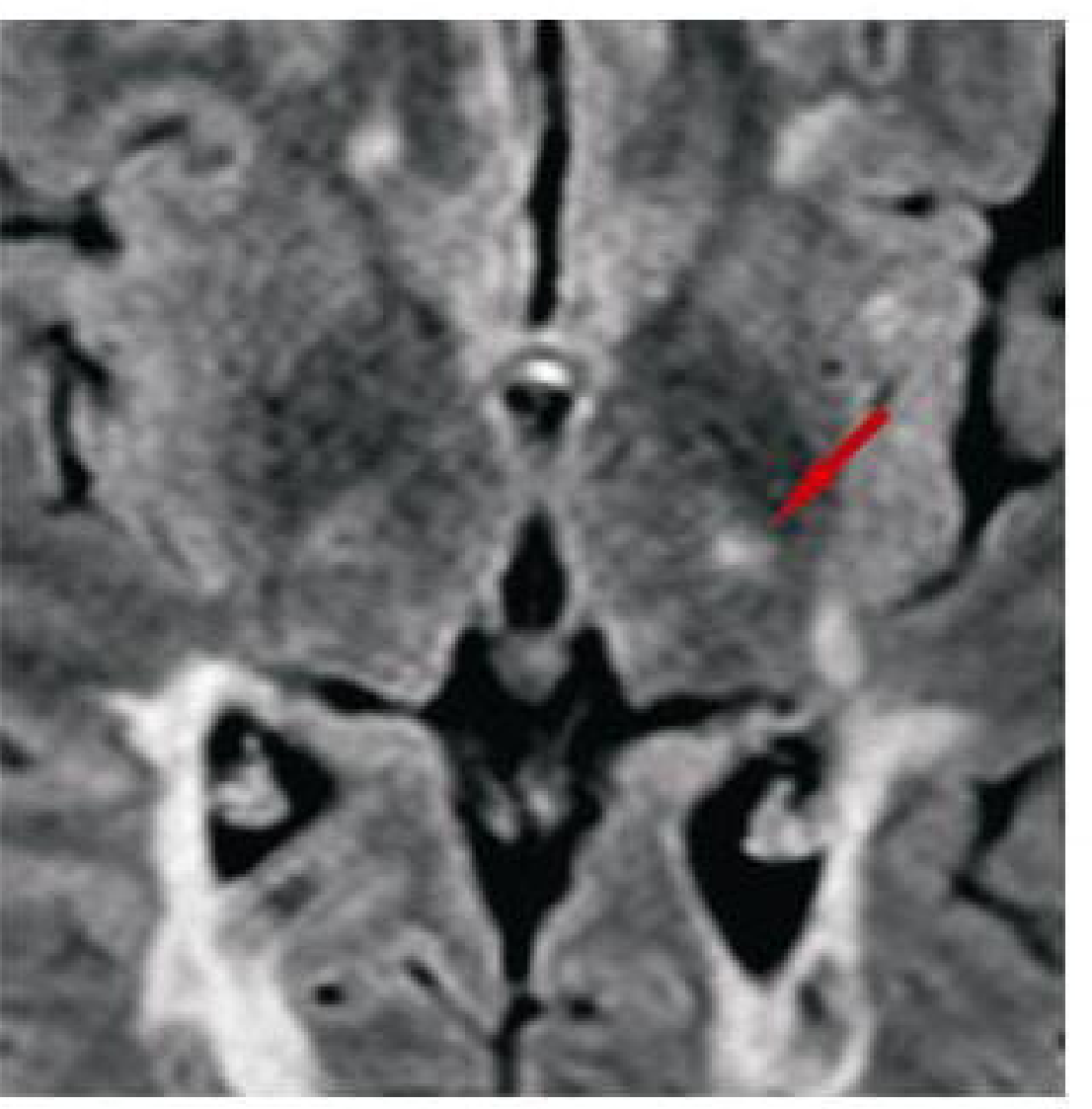

Figure 2b

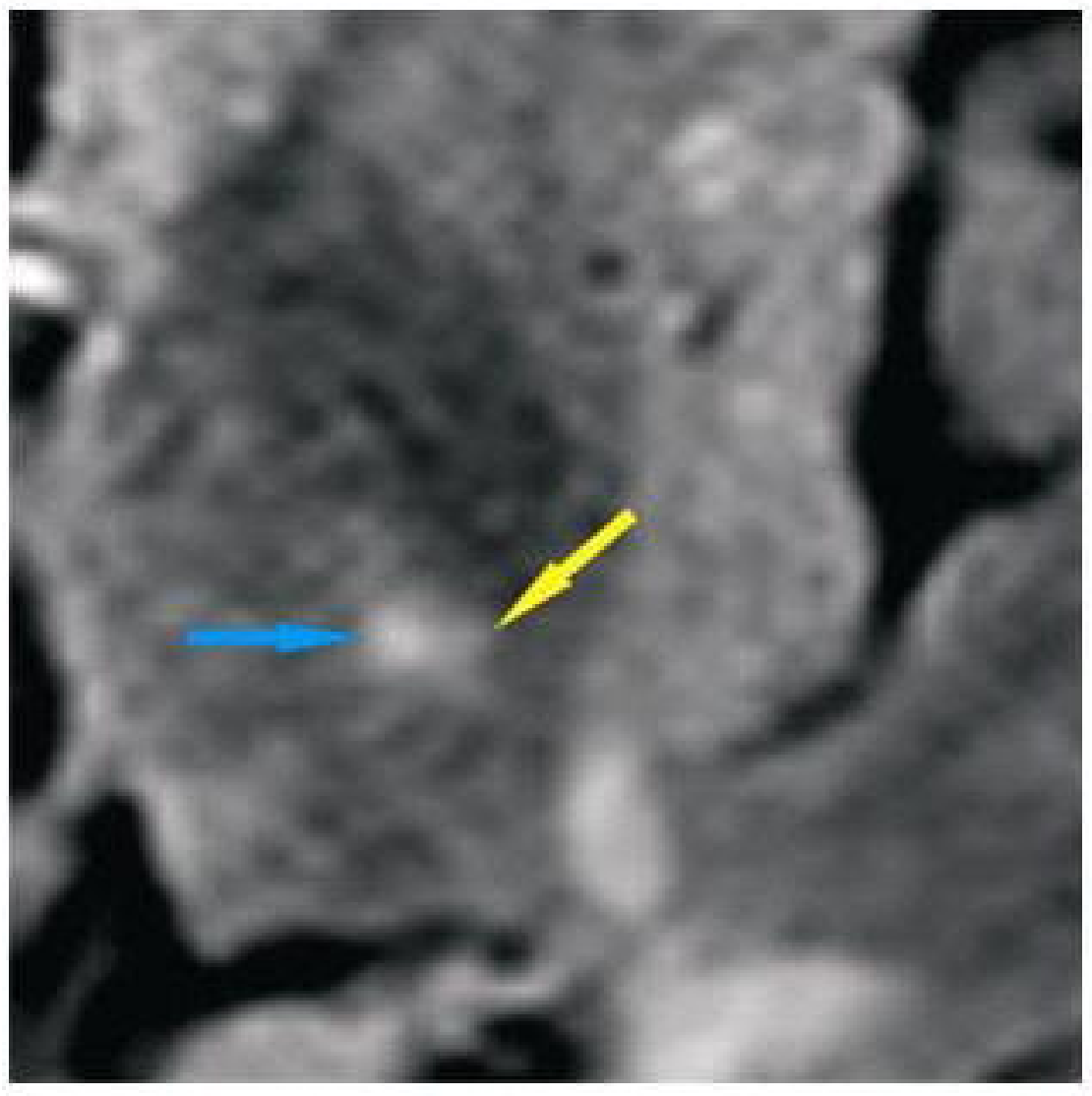

Figure $2 \mathrm{c}$

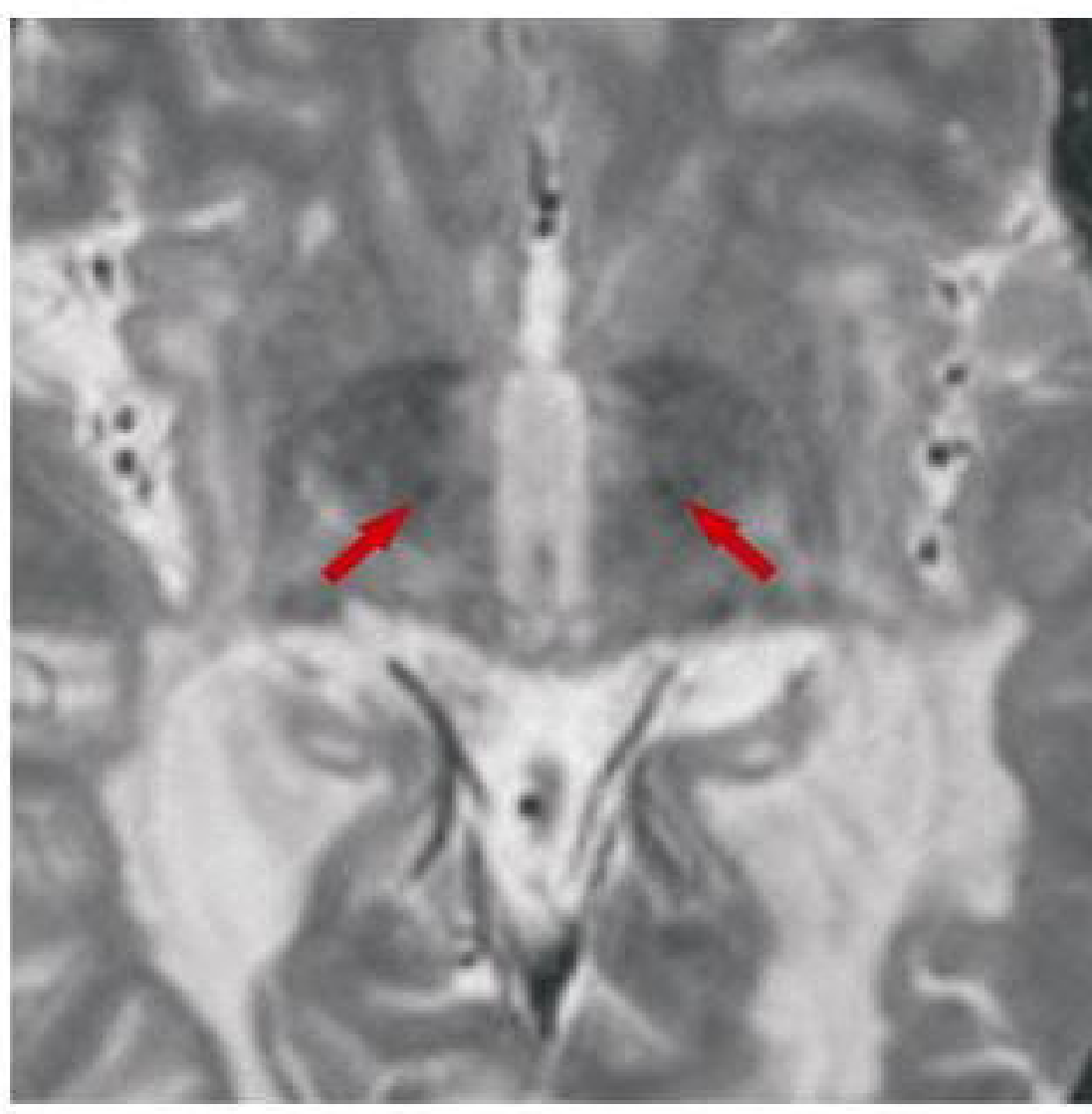

